\title{
Interactive comment on "The recent state and variability of the carbonate system of the Canadian Arctic in the context of ocean acidification” by Alexis Beaupré-Laperrière et al.
}

\section{Anonymous Referee \#2}

Received and published: 24 March 2020

The Arctic Ocean is particularly vulnerable to acidification due to its relatively low buffering capacity and, thus is considered as a bellwether to study global ocean acidification. The manuscript "The recent state and variability of the carbonate system of the Canadian Arctic in the context of ocean acidification" written by Alexis BeaupréLaperrière et al, descripts characteristics of carbonate system in the Canadian Arctic Archipelago and its adjacent Canada Basins in the recent 5 years. However, the MS needs to be majorly revised as to answer those questionnaires such as the follows: 1iijöThe abstract needs to rewrite as to focus on important conclusions and avoid too much descriptive. 2iijőLack of nutrient DO and other auxiliary parameters data. This is odd, because these parameters are usually obtained at the same time as

Printer-friendly version

Discussion paper 
the carbonate system. This also leads to the discussion of this article is not strong. 3iiijÖAlthough this article is logically organized, it seems that there is too much information that is not important which affects the reader's reading. Specific comments: 1. Suggest change the title of "Canadian Arctic" to "Canadian Arctic Archipelago and adjacent Basins". 2. The abstract is poorly written. There are too many summaries of the previous work, and the conclusion and discussion should be mention more. 3. The CCGS appears for the first time, giving it its full name. 4. In figure 1, blue and red lines can be used to represent the direction and scope of influence of Pacific water and Atlantic water respectively. 5. The color bar in figure 4 represents the suggested source in red for easy identification 6 . In figure 5 , there are only two colors of red and blue, so it is difficult to see the regional difference. It is recommended to use a variety of color gradients to distinguish. 7. Line 270 should be Fig. 6b, c. 8 . What does the color difference mean in Figure 7? Suggestions clearly marked. 9. Line 325 aragonite saturation coincide with the temperature maximum but $\mathrm{pH}$ does not. 10. From 460 to 465 lines, this part should be an important highlight of this article, it is suggested to strengthen the discussion. 11. Line 485-495iijNThe author's description of the calculation method is not clear enough. My understanding is to calculate $\mathrm{pCO} 2$ by DIC and TA in the starting year, and then assume that the change of atmospheric $\mathrm{CO} 2$ is synchronized with the change of water body, calculate the DIC value only affected by the atmosphere in given year, and finally use the measured DIC minus DICatmosphere =delta DICorganism? 12. Line 520, Fig. 14 or Fig. $12 i i j \S$ 13. Suggest moving the Appendix to method. 14. It is shocking and strange that this MS does not mention this article: Azetsu-Scott, Kumiko, Calcium carbonate saturation states in the waters of the Canadian Arctic Archipelago and the Labrador Sea

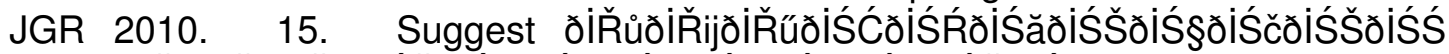
and ðiŘůoiŘijoiruúðiśĚðiśšðiśşðiśšðiś§ðiśšðiśżðiśŘðiśš to simplify into

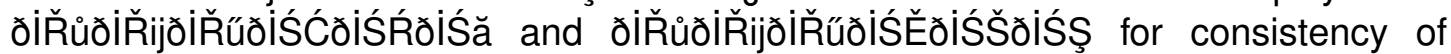

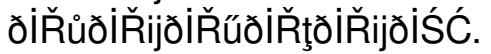

Printer-friendly version

Discussion paper 
Interactive comment on Biogeosciences Discuss., https://doi.org/10.5194/bg-2020-29, 2020.

Interactive

comment 